\title{
Ranking of Vitrified Grinding Wheel Parameters by using Analytical Hierarchical Process (AHP) for Surface Roughness of Work Piece in Grinding Operation
}

\author{
Sanjay S Patil ${ }^{1}$ \\ PhD Research Scholar \\ MIT, Kothrud, \\ Pune, India. \\ E-mail: sspatil.scoe@sinhgad.edu
}

\author{
Yogesh J. Bhalerao ${ }^{2}$ \\ Principal, \\ MIT Academy of Engineering, Alandi, \\ Pune, India. \\ E-mail:ybhalerao@maepune.ac.in
}

\begin{abstract}
Objective of grinding process is to generate high quality surface finish on work piece. There are many parameters which influence on the work piece roughness. Work piece material and characteristics, grinding wheel specification, grinding conditions and dressing conditions influence on the surface quality of the work piece. Selection of grinding wheel is important aspect for producing good quality of surface finish on the work piece. The main components of grinding wheel are the abrasive grains, bond material and porosity. Selection of correct grinding wheel is necessary for generating better surface finish on the work piece. Analytical Hierarchical Process (AHP) is used for ranking of vitrified bond grinding wheel parameters on surface roughness on the work piece in sub sequent grinding operation. The grit, grade, (Hardness of wheel) structure and type of abrasive are critically assisted in terms of the surface finish produced on work piece in the subsequent grinding operation. Analytic Hierarchy Process (AHP) shows that the abrasive grit of grinding wheel has first rank and grade (hardness) of the wheel has Second rank for the producing surface finish on the work piece after grinding operation. Structure and type of abrasive of wheel have a third and fourth rank respectively. Thus, AHP gives qualitative way of controlling work piece surface roughness in sub-sequent grinding operation by selecting proper grinding wheel of vitrified bond which helps the user to select the correct grinding wheel.
\end{abstract}

Keywords- Grinding operation, grinding wheel, Ranking, surface finish, Analytical Hierarchical Process (AHP).

\section{INTRODUCTION}

Grinding is the metal cutting process which is mainly used in automobile sectors for producing better quality surface on parts with high accuracy, high form and to close tolerances. There are many types of grinding wheels which are varying from each other. Grinding wheel design varies according to their use. It should be easy to use grinding wheel by the end user and end user should be comfortable with applications of grinding wheel for his intended purpose. There is difficulty in transferring laboratory results to the actual practice. But there is a need to understand grinding wheel parameters to the end user. Once end user start understanding about grinding wheel parameters then he can make best use of available resources for producing quality surfaces on the work piece. In actual practice, End user does not have enough information about grinding wheel parameters.

It is necessary to understand the present industrial sceneries in the field of grinding development. Academic research should help for reducing industrial challenges in the field of grinding. The key factors are generally associated with selection of proper grinding wheel. The performance of grinding process mainly depends on selection of correct grinding wheel, work piece characteristics, grinding process parameters and dressing parameters etc.

A Grinding wheel essentially consists of a large number of abrasive particles, called grains, held together by a suitable agent called the bond. A grinding wheel consists of the type of the abrasive material used. The abrasive wheel is usually mounted on some form of machine adapted to a particular type of work. The wheel may consist of one piece or of segments of abrasive blocks built up into a solid wheel.

Abrasive grains, bond material and porosity are main components' of the Grinding wheel. As shown in fig. 1 grinding wheel components namely abrasive grains, bonding material and porosity. (voids) Fig. 1 shows the Scanning Electron Micrograph of particular grinding wheel components which are clearly visible.



Fig. 1. SEM micrograph of a grinding wheel. 
It is necessary to have key information of grinding wheel to end user. Grinding wheel specification are defined by American National Standards Institute (ANSI).Specification of grinding is also called as standard marking system of grinding wheel. The grinding wheel standard marking system explains the type of abrasive contained in the wheel size of abrasive (grit), grade or hardness of wheel, type of bond, structure of the wheel and dimensions of wheel.

There are various types of bond like shellac, resonid, rubber etc. but contributions of vitrified alumina grinding wheel are more than the $50 \%$ in precision grinding. So it is necessary to be more aware about vitrified grinding wheel to end user. The size of abrasive grain play an important role in producing surface quality on the work piece. The grain size of the abrasive of grinding wheel is called as grit and grit is classified by international mesh size in mesh/inch. Grit is varied from 8 (coarse) to 1200, (super fine). Each grit has its own application. There are coarse, medium, fine and very fine grains based on mesh size. Material removal rate and surface quality is produced on the work piece depends upon grit. If the grit is coarse, material removal rate is fast and rough quality of surface produced on the work piece and fine grit produces high surface quality on the work piece. Again there are mainly three grades of wheel. i.e. soft, medium and hard. Surface qualities of ground parts also depend on also grade (hardness) of the wheel.

A grade of wheel is also called as hardness of the wheel. which means how securely the abrasive grains are held by the binder. It has a no any relation with hardness of abrasive used in grinding wheel. Quantity of binder used in the grinding wheel decides the grade of grinding wheel. If quantity of binder is a more in a wheel then it automatically reduces the percentage of ports in the wheel and grade of grinding wheel is hard. Grade of the wheel is specified by letters A to Z. A letter means grinding wheel is very soft and $\mathrm{Z}$ letter means grinding wheel is very hard. A grade wheel contains more porosity and less bond material while $\mathrm{Z}$ grade wheel has percentage of bond is more and percentage of porosity is very less. Structure of grinding wheel is spacing of abrasive in the grinding wheel. If the structure number of grinding wheel is in the range of $1-8$, it means that the abrasives are dense in the grinding wheel where as it is range of 9 - 15 it means that the abrasive are least dense in the grinding wheel.

\section{LITERATURE SURVEY}

Fritz K Locke et al. (2016) developed a method to simulate a detailed 3- D model of the grinding wheel structure. They used volumetric composition which includes no. of grins, their orientation; their distribution in grinding wheel. Distribution of grinding wheel is decisive for its structure and topography properties. This research work is focused on creation of $3 \mathrm{D}$ model of grinding wheel structure which reflects realistic distribution of grinding wheel components, grains, bond and pores deepening on their volumetric fraction. The 3D model has been developed to measure and transfer the shape of Cubic Boron Nitride (CBN) grains. In addition, a method has been created numerically for realistic CBN grains.

A. Fritsche and F. Bleicher (2015) focused on evaluating and influencing dressing results by changing the grain size distribution based on statistical and experimental investigation. If manufacturing industry wants to remain in competition and sustain in market then they need to kaizen in their product and process. In this regard abrasive industries do higher productivity and less consumption of grinding wheel by reducing cycle of dressing operation. Three dimensional micro co-ordinate optical systems are used for analyzing the grinding wheel topography after dressing process. They developed "Active Grain Stack" (AGS) model which give information of a structure of grinding wheel and how different layers interact with each other.

Miranda et al. (2015) presented a method to evaluate the wear of single point dresser based on a frequency study of raw acoustic emission and vibration signals. They discussed significance of dressing and truing operations. If dressing and truing is not carried out frequently, then it has a effect on surface quality of the ground work piece. The aim of their work was to predicate the wear level of single point dresser based on acoustic emission and vibration signals used as input variables for fuzzy models

Novoselov, Bratan and Bogutsky (2016) presented that the predication of wear of tool is only possible based on modeling the regularities of work of single abrasive grain.. They concluded that the grain wear is constantly increased, dulled tops of the grinding wheel stop to cut and it leads to the decreasing process efficiency.

Need of the present research work:

After doing extensive industrial survey and reviewing the literature, it is found that there is correlation between grinding wheel parameters and surface finish produced on work piece in sub-sequent grinding operation. There is certain influence of wheel parameters on the quality of surface finish produced on the work piece in sub-sequent grinding operation.

Very few researchers have worked parameters of grinding wheel Therefore there is a need to develop the hierarchical structure for the grinding wheel which consider critical assessment of grinding wheel parameters and also rank the parameters. Once end user knows the ranking of parameters of grinding wheel then he can easily select the grinding wheel for roughing or finishing. By controlling the ranked parameter, surface finish of desired quality on the work piece can be obtained which is objective of grinding process.

THE ANALYTIC HIERARCHY PROCESS (AHP)

The Analytic Hierarchy Process (AHP) is a common m e th o d developed by Saaty (1980) for support multi 
criteria decisions, steps of AHP process are implemented for grinding wheel parameters.

\section{STEPS OF THE AHP PROCESS FOR RANKING OF GRINDING WHEEL PARAMETERS}

Selecting of grinding wheel parameters -

By doing extensive industrial surveys and reviewing the literature, four parameters of the grinding wheel are considered for the present research work. They are:

I. Abrasive Grit

II. Grade (hardness) of grinding wheel

III. Structure of grinding wheel

IV. Type of abrasive

AHP steps implemented are as follows:

Step 1:

Let us represent,

$\mathrm{A}=$ Abrasive grit,

$\mathrm{B}=$ Grade of grinding wheel,

$\mathrm{C}=$ Structure of grinding wheel,

$\mathrm{D}=$ Type of abrasive

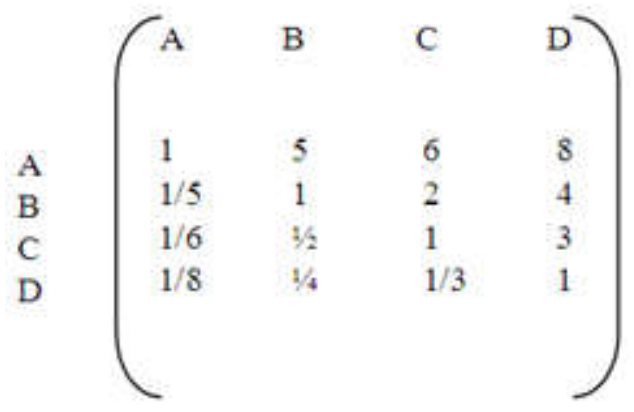

Sum of Abrasive grit $(A)=1.4816$,

Sum of Grade of Grinding Wheel $(\mathrm{B})=6.75$,

Sum of Structure of grinding wheel $(\mathrm{C})=9.333$,

Sum of Type of abrasive (D) $=16$.

\section{Step 2:}

Average Abrasive grit $(\mathrm{A})=0.6384$,

Average Grade of Grinding Wheel $(\mathrm{B})=0.1866$,

Average Structure of grinding wheel $(\mathrm{C})=0.1201$,

Average Type of abrasive (D) $=0.0544$.

A weight vector $\mathrm{w}=[0.6384,0.1866,0.1201,0.0544]$

Step 3:

$\begin{aligned} & \mathrm{A} \\ & \mathrm{B} \\ & \mathrm{C} \\ & \mathrm{D}\end{aligned} \quad\left(\begin{array}{cccc}1 & 5 & 6 & 8 \\ 1 / 5 & 1 & 2 & 4 \\ 1 / 6 & 1 / 2 & 1 & 3 \\ 1 / 8 & 1 / 4 & 1 / 3 & 1\end{array}\right) *\left(\begin{array}{c}.6384 \\ .1866 \\ .1201 \\ .0529\end{array}\right)=\left(\begin{array}{l}2.7276 \\ 0.7741 \\ 0.4854 \\ 0.2204\end{array}\right)$

Step 4:

$$
\left(\begin{array}{l}
2.7276 \\
0.7741 \\
0.4845 \\
0.2204
\end{array}\right) \div\left(\begin{array}{l}
0.6384 \\
0.1866 \\
0.1201 \\
0.0544
\end{array}\right)=\left(\begin{array}{l}
4.2725 \\
4.1844 \\
4.0341 \\
4.0218
\end{array}\right)
$$

Mean $=4.12$

If Consistency Index $=0$ then, $\mathrm{A}$ is consistent;

If Consistency Index /Random Index $\leq 0.10$ then, $A$ is consistent enough,

If Consistency Index / Random Index $>0.10$, then A is seriously inconsistent.

C.I $=(4.12-4) / 4=0.03$

From table 2, for $n=4$, value of Random Index $=0.90$

Now Consistency Index / Random Index $=0.03 \div 0.90$

$$
=0.0333<0.10
$$

Based on the above calculations, we conclude that matrix is consistent enough.

As, $\mathrm{W}=[0.6384,0.1866,0.1201,0.0544]$

Ranking of vitrified grinding wheel parameters are critically a ssisted in terms of surface finish produced on the work piece in the grinding operation and ranking are as follows.

Rank 1. Abrasive grit

Rank 2. Grade of grinding wheel

Rank 3. Structure of grinding wheel

Rank 4. Type of abrasive

Graph for parameters (As shown in fig. 2)
A. Abrasive grit.
B. Grade of grinding wheel
C. Structure of grinding wheel
D. Type of abrasive 


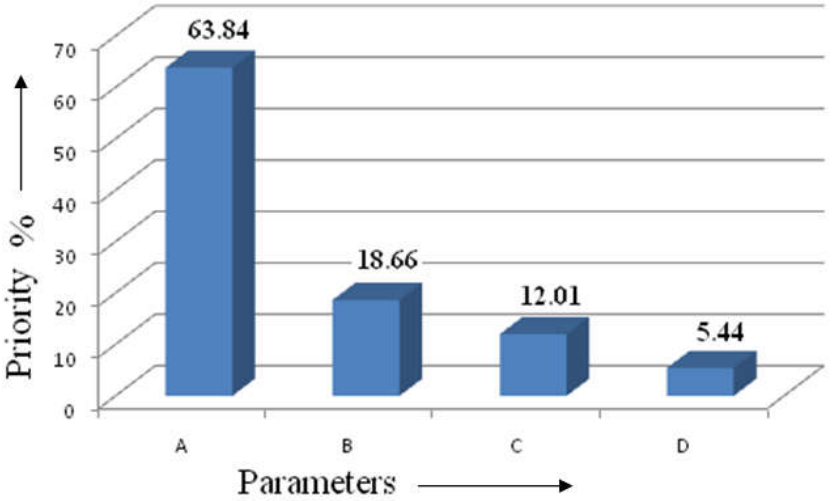

Fig. 2. Ranking of Grinding Wheel Parameters.

\section{CONCLUSION}

The ranking of parameters of grinding wheel namely abrasive grit (A), Grade of abrasive,(B), Structure (C) and Type of abrasive (D) for the surface finish produced on the work piece in subsequent grinding operation have done by Analytic Hierarchy Process. The order of ranking descends as follows i) abrasive grit of grinding wheel ii) grade of grinding wheel iii) structure of wheel \& iv) type of abrasive of grinding wheel. Thus, AHP gives qualitative way of controlling work piece surface roughness in sub-sequent grinding operation by selecting proper grinding wheel of vitrified bond which helps the user to select the correct grinding wheel.

\section{ACKNOWLEDGMENT}

Authors would like to express their sincere gratitude to Mr. Prakash Patil, Senior Manager, Grindwell Norton Limited- Abrasive Solutions, Pune, India and all other domain experts for providing their expertise in the development of proposed ranking of grinding wheel parameters.

\section{REFERENCES}

[1] Patil.S.S, Katikar R.S, Determining The Ranking Of Dressing Parameters For Grinding Ratio In Surface Grinding By Analytical Hierarchical Process (Ahp), International Journal of Research in Engineering \& Applied Sciences. Volume 2, Issue 2, 2012,pp641-650

[2] Omkarprasad S. Vaidya, Sushil Kumar," Analytic hierarchy process: An overview of applications". $\quad$ European Journal of Operational Research 169 (2006) 1-29

[3] Loan D. Marinescu,Mike Hitchiner,Eckart Uhaman,W.Brian Rowe, Ichiro Ichiro Inasaki," Hand book of Machining with Grinding Wheel"CRC Press, Taylor \&Fraancis Group.

[4] Saaty T.L., Analytical Hierarchical Process, Tata McGraw hill Publication.

[5] A.Fritsche, F.Bleicher," Evaluating and Influencing Dressing Results by Changinize g the Grain Distribution Based on Statical and Experimental Investigations. 12th Global Conference on Sustainable Manufacturing. Procedia CIRP 26(2015) 718-723.

[6] Miranda, H.I., Rocha, C.A., Oliveira Jr, P., Martins, C., Aguiar, P.R., Bianchi, E.C., "Monitoring single-point dressers using fuzzy models" 9th CIRP Conference on Intelligent Computation in Manufacturing Engineering - CIRP ICME'14, Procedia CIRP 33 (2015) 281-286

[7] Yu Novoselov, S. Bratan, V. Bogutsky, "Analysis of Relation between Grinding Wheel Wear and Abrasive Grain Wear." International Conference on Industrial Engineering, ICIE2016.Procedia Engineering 150 (2016) 809-814.

[8] Patil S.S., Bhalerao Y.J."Determining of optimum level (conditions) of dressing parameters for work piece surface roughness in surface grinding Operation" International Conference of Advance in Tribology, (ICAT-2014),2024Febuary2014,NIT,Ccalicut,Kerala. 